\title{
Longitudinal study of first phase insulin release in the BB rat
}

\author{
S. Reddy, N.J. Bibby, S. L. Fisher and R. B. Elliott \\ Department of Paediatrics, University of Auckland School of Medicine, Auckland, New Zealand
}

\begin{abstract}
Summary. First phase insulin release was measured in response to intravenous glucose given weekly from approximately day 40 in $6 \mathrm{BB}$ rats which subsequently developed diabetes and in age-matched non-diabetic $(n=15)$ and normal Wistar rats $(n=8)$ until day 180 . The mean sequential insulin responses in $\mathrm{BB}$ rats with and without diabetes were significantly lower ( $p=0.008$ and $<0.0001$, respectively) than in normal rats from an early age. Five diabetic BB rats showed a progressive decline in first phase insulin release immediately prior to glycosuria, with the impaired phases ranging from 25-50 days. However, protracted periods of low first phase responses were also seen in several aglycosuric BB rats, which
\end{abstract}

showed histological evidence of insulitis and B-cell loss. Our findings demonstrate that, although most BB rats with diabetes show a progressive impairment of B-cell function preceding the disease, this aberrant phase can also be present in BB rats which remain aglycosuric. Impaired first phase insulin release in response to serial intravenous glucose tolerance tests may not be a reliable predictor of Type 1 (insulin-dependent) diabetes in this animal model.

Key words: BB rats, intravenous glucose tolerance tests, first phase insulin release, immunofluorescence.
The onset of Type 1 (insulin-dependent) diabetes mellitus in the BB rat is usually abrupt at some stage between 40 and 180 days of age $[1,2]$. Both cell-mediated and humoral immunity have been implicated in the etiology of diabetes in this animal model [3-9]. Recently autoantibodies directed against a normal rat islet antigen have been shown to precede the onset of the disease in almost all susceptible animals [7]. However, tests which are convenient and predictive of spontaneous diabetes in the BB rat have yet to be developed. Serial pancreatic biopsies from these animals examined longitudinally suggest that mononuclear cell infiltrations of the islets can precede the onset of overt diabetes by at least 2-3 weeks [10]. To what extent these inflamatory processes affect B-cell number or function during the prediabetic phase is unclear. Recent studies in the human suggest that subjects who are at risk of developing Type 1 diabetes may show a progressive loss of first phase insulin release in response to intravenous (IV) glucose well before clinical diagnosis [11,12].

The present study was undertaken in the $\mathrm{BB}$ rat to determine if a progressive impairment of B-cell function could be demonstrated prior to clinical onset of Type 1 diabetes. We assessed B-cell function by measuring first phase insulin release in response to weekly in- travenous glucose tolerance tests (IVGTT) in BB rats from about day 40 until the detection of glycosuria and in age-matched non-diabetic BB and normal Wistar rats until day 180.

\section{Materials and methods}

The experimental animals studied were diabetes-prone BB rats (25-40\% diabetes incidence) which were derived from the original BioBreeding colony, Ottawa, Ontario, Canada and normal Wistar rats.

Serial IVGTTs were carried out weekly in non-diabetic BB and normal Wistar rats from day 40 to day 180 and in diabetic BB rats from day 40 until the onset of Type 1 diabetes (persistent glycosuria: 3-4+). After an overnight fast, a $50 \%$ solution of glucose $(1 \mathrm{~g} / \mathrm{kg}$ body weight) was injected into the tail vein over $15-20$ s under light halothane anaesthesia. Blood was sampled from the orbital sinus at 1 and $3 \mathrm{~min}$ after injection and sera stored at $-20^{\circ} \mathrm{C}$ until analysis.

In order to establish the normal dynamics of insulin release in vivo, 5 normal Wistar rats were fasted overnight and challenged with IV glucose according to the above protocol and blood was sampled from the orbital sinus at $1,3,5,10,15,20$ and $30 \mathrm{~min}$ after injection.

Immunoreactive insulin (IRI) was measured in serum by a single antibody polyethylene glycol separation method (in routine use in this laboratory) using human insulin standard (Wellcome, Beckenham, UK), guinea pig anti-human insulin serum (Wellcome) and ${ }^{125} \mathrm{I}-$ porcine insulin tracer. In this assay rat insulin (Novo, Bagsvaerd, Denmark) was 1.5 times more immunopotent than the human insulin standard. 
Serum glucose was determined by a commercially available glucose oxidase method (Peridochrom, Boehringer, Mannheim, FRG).

Normal Wistar and BB rats without diabetes were killed at day 180 , while diabetic $\mathrm{BB}$ rats were killed soon after detection of glycosuria. All pancreata were removed immediately and fixed in Bouin's fluid and prepared for histology (haematoxylin and eosin $(\mathrm{H}$ and E) and aldehyde thionine stains). Sections were also stained simultaneously for insulin and glucagon by a previously described im-

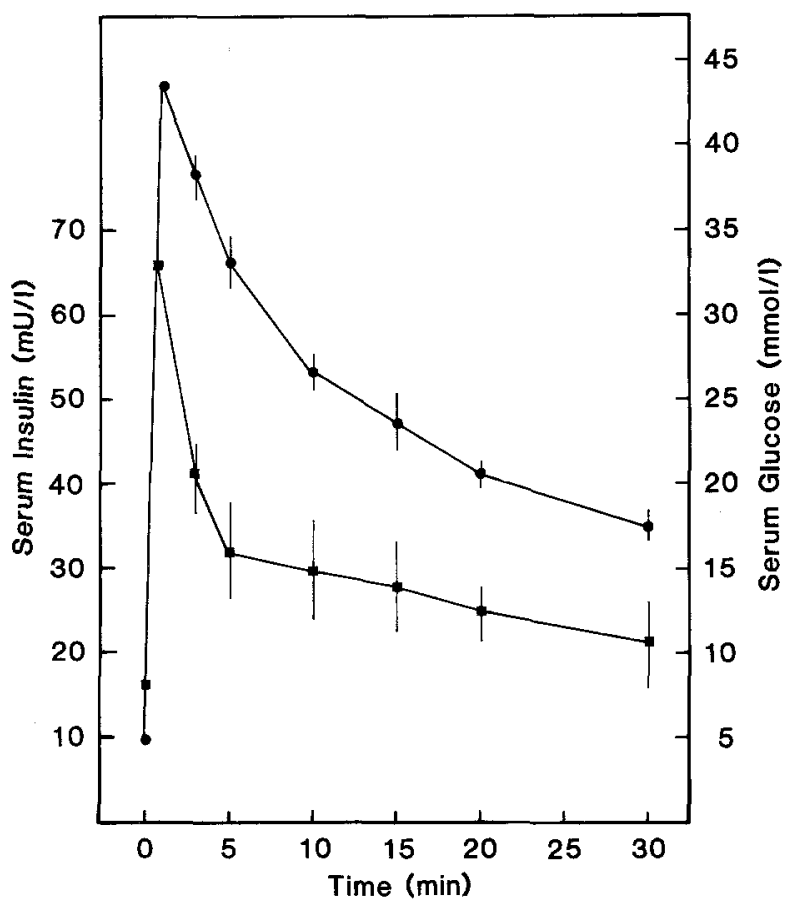

Fig. 1. Dynamics of insulin release in response to IV glucose in fasting Wistar rats. A $50 \%(\mathrm{w} / \mathrm{v})$ solution of glucose $(1 \mathrm{~g} / \mathrm{kg}$ body weight) was injected into the tail vein and sera assayed for insulin (- and glucose (-) at the times shown. Each value represents the mean \pm SEM of 5 rats (age: 93, 105 (2 animals), 130 and 155 days) munofluorescence procedure with minor modifications [13]. A mixture of guinea pig anti-insulin and rabbit anti-glucagon sera $11: 80$ dilution) was added to the sections and incubated. The immunofluorescence was observed after applying a solution of sheep anti-guinea pig gamma globulin-fluorescein isothiocyanate (Wellcome, Beckenham, UK) and swine anti-rabbit gamma globulin-rhodamine (Dako, Glostrup, Denmark) at a final dilution of $1: 20$.

\section{Statistical analysis}

First phase insulin release in all animals was defined as the sum of 1 and $3 \mathrm{~min}$ serum IRI levels after IV injection of glucose and was expressed as the mean and standard error of the mean (SEM). Tests of significance between the three experimental groups were determined by the Sign Test.

\section{Results}

Figure 1 shows the mean \pm SEM of IRI and glucose in the sera of 5 normal Wistar rats from 1-30 min following IV glucose administration. The first phase was rapid $(<5 \mathrm{~min}$ ), with peak insulin value at $1 \mathrm{~min}$, while the second phase was much more protracted and less pronounced. The disappearance of glucose from the circulation was approximately exponential (Fig.1).

Figure 2 shows the mean \pm SEM of the sequential first phase insulin responses in 8 normal rats as a function of age. Between day 34 and 83 (corresponding approximately to sexual maturity) the mean values increased gradually from $110 \mathrm{mU} / 1$ to $174 \mathrm{mU} / 1$. The responses then gradually declined to a low mean value of $54 \mathrm{mU} / 1$ at 132 days. A subsequent rise to $180 \mathrm{mU} / 1$ between day 170-180 then occurred.

In BB rats which remained aglycosuric $(n=15)$, a similar trend in the sequential responses was also apparent except towards the end of the study period

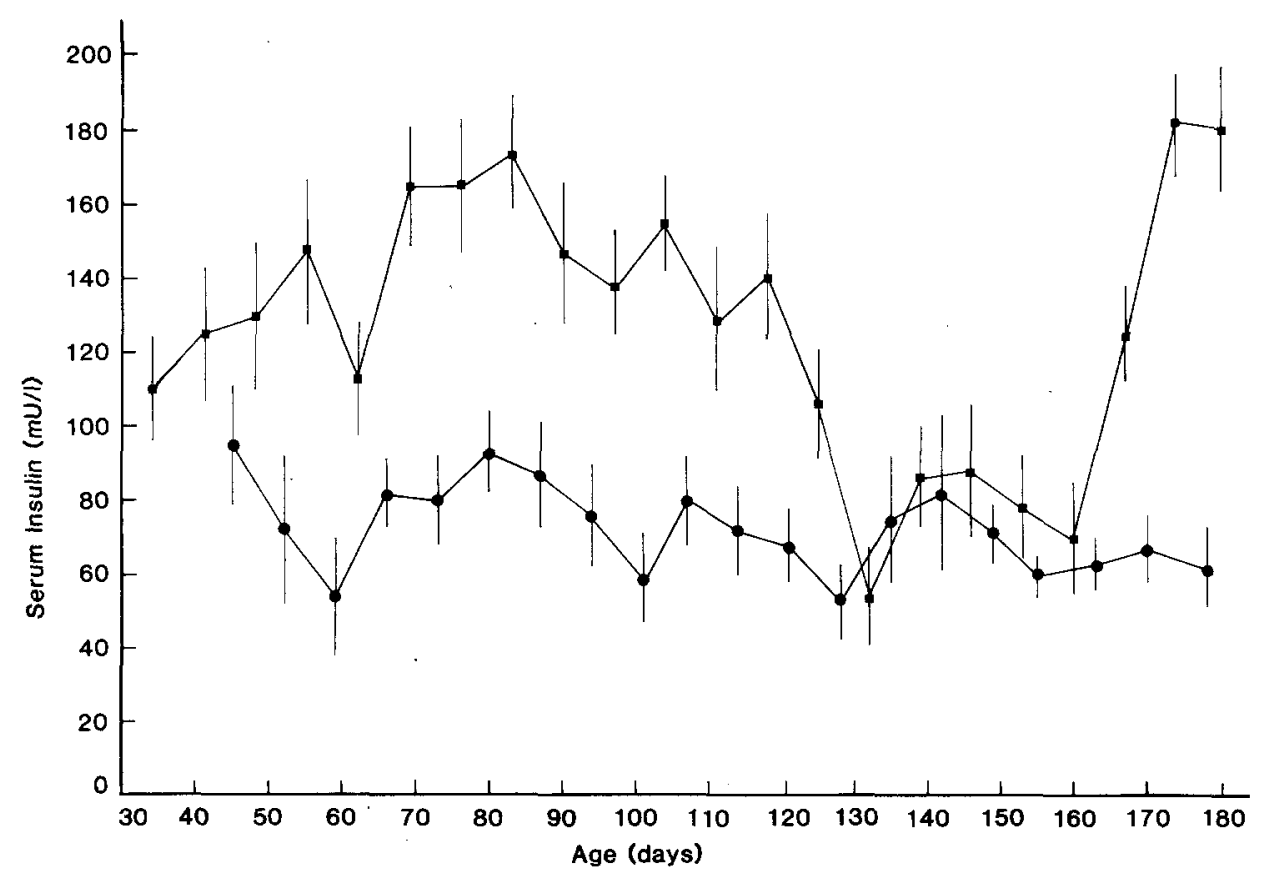

Fig. 2. The mean \pm SEM serial first phase insulin release in response to IV glucose $(50 \% \mathrm{w} / \mathrm{v}, 1 \mathrm{~g} / \mathrm{kg}$ body weight) in normal Wistar and non-diabetic BB rats. First phase insulin release was expressed as the sum of 1 and $3 \mathrm{~min}$ serum IRI levels after IV glucose injection. Upper graph (- - ) : normal Wistar rats $(n=8)$; lower graph $(\bullet-)$ non-diabetic BB rats $(n=15)$ 

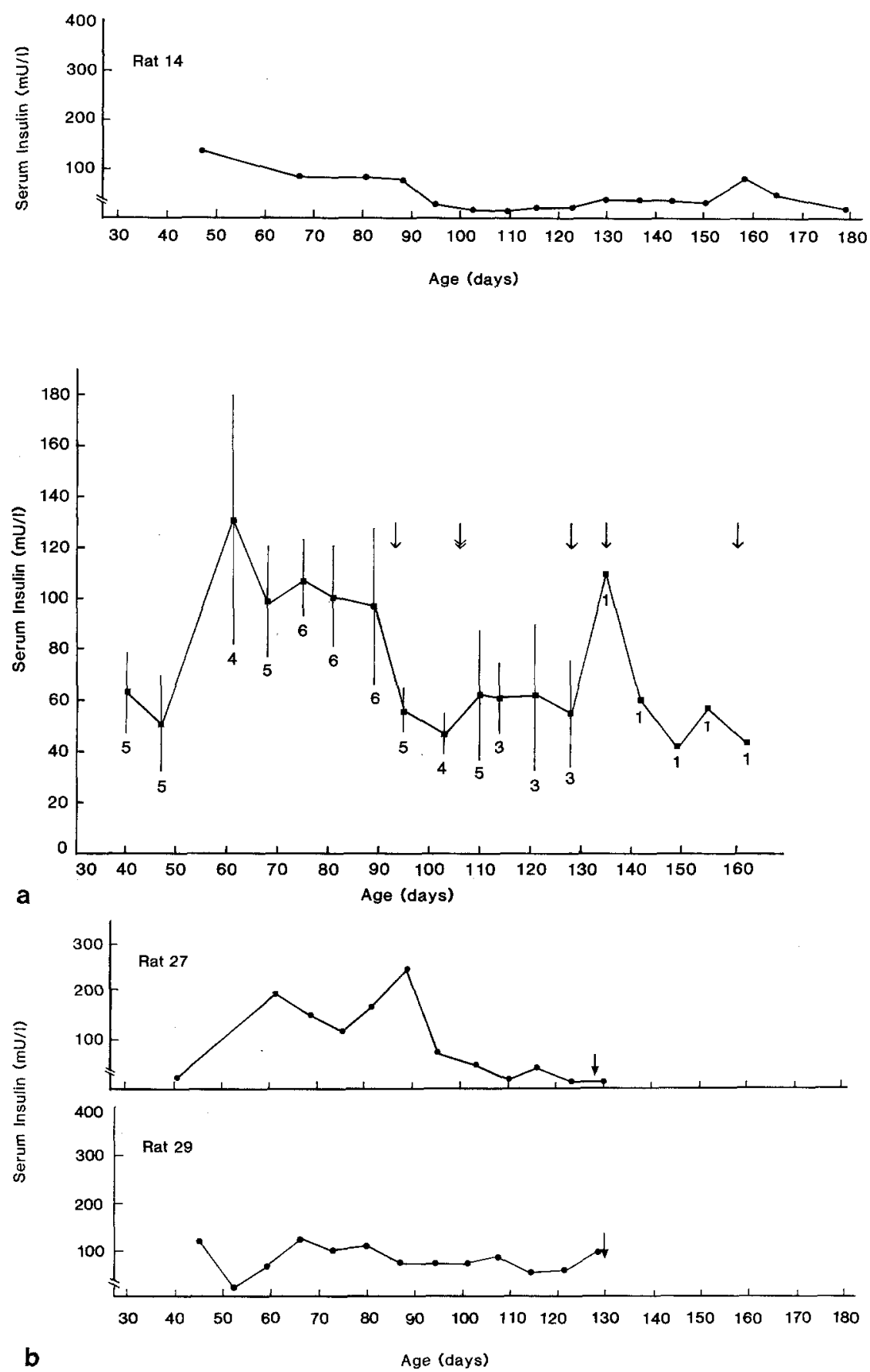

Fig.3. Serial first phase insulin release in response to IV glucose $(50 \% \mathrm{w} / \mathrm{v}, 1 \mathrm{~g} / \mathrm{kg}$ body weight) in a non-diabetic BB rat (rat 14) with a protracted period of low responses. Each value is the mean of two determinations
Fig.4. a The mean \pm SEM serial first phase insulin release in response to IV glucose $(50 \% \mathrm{~W} / \mathrm{v}, 1 \mathrm{~g} / \mathrm{kg}$ body weight) in $6 \mathrm{BB}$ rats which developed diabetes at the ages denoted by vertical arrows. First phase insulin release was expressed as the sum of 1 and $3 \mathrm{~min}$ serum IRI levels after IV glucose injection. The number below each point represents the number of animals in which IVGTTs were performed. b Serial first phase insulin release in 2 diabetic $\mathrm{BB}$ rats. A diabetic $\mathrm{BB}$ rat with a progressive decline in insulin response is shown in the upper panel, while the lower panel shows the response in an animal in which this decline was not apparent. Each point is the mean of two determinations. Vertical arrows represent the age of onset of diabetes
(Fig.2). These responses, however, were significantly lower $(p<0.0001)$ than those in normal Wistar rats. The serial values from individual aglycosuric rats showed more abrupt week to week fluctuations than in normal animals. In some BB rats without diabetes (e.g. rat 14, Fig.3) first phase release was clearly impaired for a considerably longer period (day 90-95 to day 180), but glycosuria was not detected.

Figure $4 \mathrm{a}$ shows the ages of onset and the mean \pm SEM first phase insulin responses in $6 \mathrm{BB}$ rats which developed diabetes. These responses showed a similar trend to normal Wistar rats and non-diabetic BB rats. They were, however, significantly lower $(p=0.008)$ than for normal rats but similar to BB rats without diabetes. Although individual diabetic rats showed some variations in their serial first phase insulin release, in 5 animals a period of progressive decline in these responses immediately prior to detection of glycosuria was noted (25-50 days). In the remaining animal this impaired phase preceding the disease was not seen. These features are depicted for two diabetic BB rats in Fig. 4 b.

All BB rats with diabetes displayed mononuclear cell infiltrations of pancreatic islets (Fig. $5 \mathrm{a}$ ). Most BB rats without diabetes contained the normal complement of alpha and B cells at day 180 (Fig. 5b, c). However, aglycosuric BB rats with protracted periods of low first 

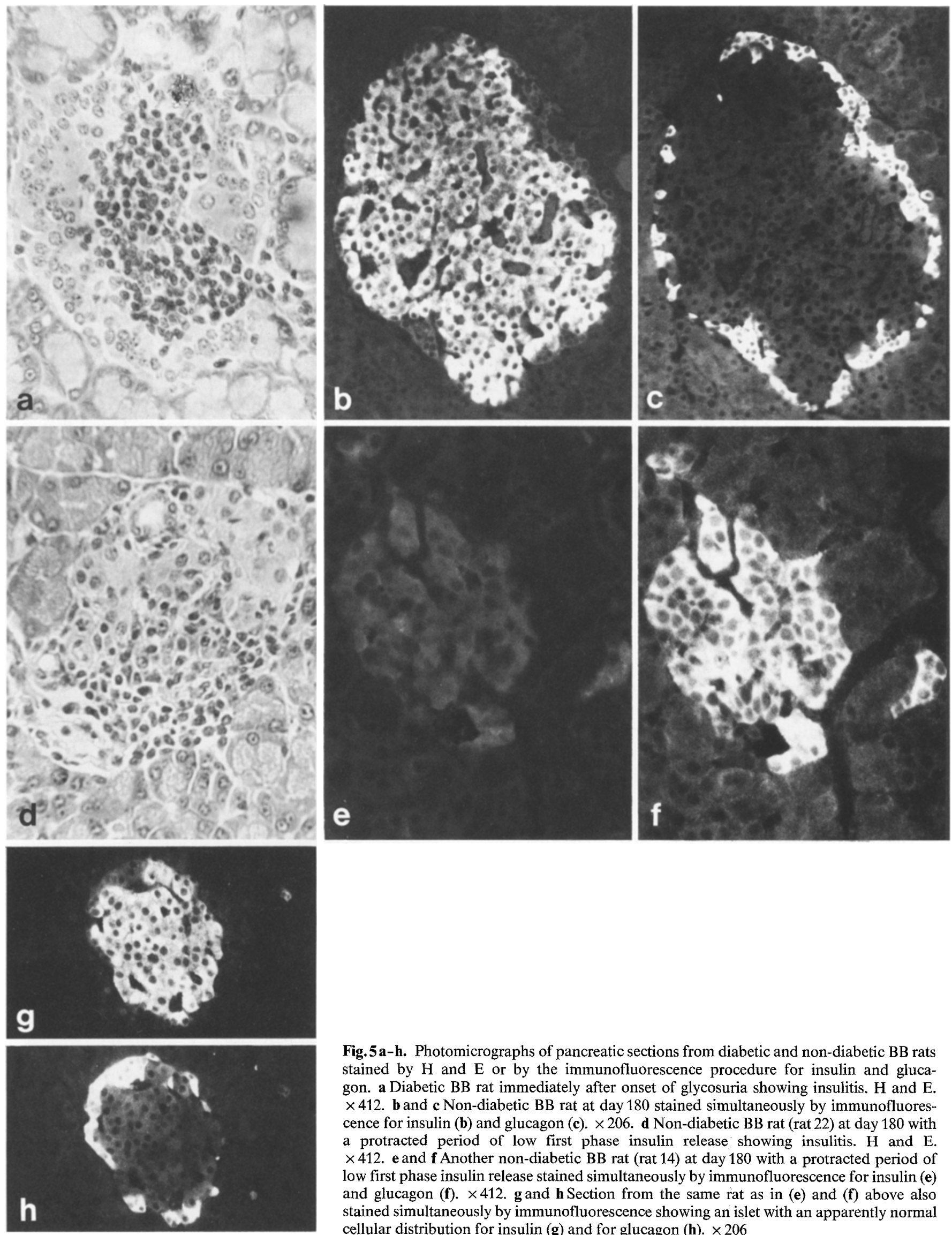

Fig. 5a-h. Photomicrographs of pancreatic sections from diabetic and non-diabetic BB rats stained by $\mathrm{H}$ and $\mathrm{E}$ or by the immunofluorescence procedure for insulin and glucagon. a Diabetic BB rat immediately after onset of glycosuria showing insulitis. $\mathrm{H}$ and $\mathrm{E}$. $\times 412$. $b$ and $\mathrm{c}$ Non-diabetic $\mathrm{BB}$ rat at day 180 stained simultaneously by immunofluorescence for insulin (b) and glucagon $(\mathbf{c}) . \times 206$. d Non-diabetic BB rat (rat 22) at day 180 with a protracted period of low first phase insulin release showing insulitis. $\mathrm{H}$ and $\mathrm{E}$. $\times$ 412. $\mathrm{e}$ and $\mathbf{f}$ Another non-diabetic BB rat (rat 14) at day 180 with a protracted period of low first phase insulin release stained simultaneously by immunofluorescence for insulin (e) and glucagon (f). $\times 412$. $g$ and $h$ Section from the same rat as in (e) and (f) above also stained simultaneously by immunofluorescence showing an islet with an apparently normal cellular distribution for insulin (g) and for glucagon (h). $\times 206$ 
phase insulin response displayed a pancreatic pathology similar to diabetic rats (e.g. rat 14 and rat 22 Fig. $5 \mathrm{~d}-\mathrm{f}$ ). In rat 22 there was evidence of insulitis, while in rat 14 pancreatic islets appeared compressed, and most were devoid of $\mathrm{B}$ cells but had a predominance of alpha cells. Only some islets had the normal complement of alpha and B-cells (Fig. $5 \mathrm{~g}, \mathrm{~h}$ ).

\section{Discussion}

Several studies have focused on the search for possible immunological, hormonal or biochemical markers predictive of diabetes in the BB rat $[3,6-9,14,15]$. However, there are only a few studies which have described insulin secretory capacity in response to suitable secretagogues in this animal model. Using the perfused pancreas, it has been shown that BB rats with protracted periods of glucose intolerance display suppression of the early and late phases of IRI in response to glucose [16]. In another report, insulin secretion in response to single IVGTT was conducted 10-28 days before onset [14]. However, in these studies were not determined serially and the failure to observe any significant changes in insulin secretion may have been due to the prolonged glucose pulse (120 s compared with $20 \mathrm{~s}$ in this study) and the infrequent blood sampling immediately after glucose injection, thus missing the first phase. In the present investigation on the $\mathrm{BB}$ rat, we have examined first phase insulin secretion in response to serial IV glucose in vivo.

The biphasic pattern of insulin release in normal rats following an IV glucose challenge shown here confirms previous studies [17]. In this group the mean sequential responses were significantly higher than in BB rats. However, the physiological significance of the decline in the mean responses after day 125 and then a rise is unclear.

The mean serial responses of first phase release were significantly lower in BB rats with or without diabetes compared with normal animals. Some non-diabetic BB rats displayed periods of progressive loss of first phase insulin release with intermittent recovery while others had a much more protracted period of successive low response not associated with glycosuria. The pancreatic pathology at day 180 of these latter animals was similar to diabetic rats and is in agreement with previous reports [8]. These findings suggest that some aglycosuric BB rats, despite considerable B-cell depletion, may have enough pancreatic insulin to maintain normoglycaemia.

Five out of 6 BB rats with diabetes showed a progressive loss of first phase insulin release immediately prior to onset. However, the duration of this impaired phase was variable and is probably a reflection of different rates of B-cell damage. The lack of any significant differences in the mean responses between diabetic and non-diabetic groups suggests that in most BB rats there may be an underlying B-cell functional defect from an early age and that other variables are responsible for triggering diabetes in only some animals. It is notable that immunological abnormalities such as the presence of islet cell surface antibodies in serum and lymphopaenia can be a feature of diabetic and non-diabetic $\mathrm{BB}$ rats $[8,9]$.

In humans, only a few studies have examined first phase insulin release prospectively from the pre-diabetic phase to clinical diagnosis $[11,12]$. Although these investigations were determined on a limited number of patients, it was nevertheless shown that there was a progressive loss of first phase insulin release in response to serial IVGTT over several months or years. In this study on the BB rat, we have also demonstrated an increasingly impaired first phase insulin release immediately before clinical onset but this aberrant phase was also seen in several aglycosuric BB rats. Consequently, a decrease in first phase insulin release in response to serial IV glucose is not a reliable predictor of Type 1 diabetes in this animal model.

Acknowledgements. We thank Ms. M.Evans for supplying the insulin tracer, Ms. V.Stewart and Ms. C. Coppersmith for typing the manuscript and Ms. L. Logan and P. Hurst for the photographic work. We are also grateful to Mr. A. Stewart and Mr. B. Edgar for statistical advice. This study was financed by the National Children's Health Research Foundation of New Zealand.

\section{References}

1. Nakhooda AF, Like AA, Chappel CI, Wei C-N, Marliss EB (1978) The spontaneously diabetic Wistar rat (the "BB" rat). Studies prior to and during development of the overt syndrome. Diabetologia 14: 199-207

2. Seemayer TA, Tannenbaum GS, Goldman HY, Colle E (1982) Dynamic time course studies of the spontaneously diabetic BB Wistar rat III. Light microscopic and ultrastructural observations of pancreatic islets of Langerhans. Am J Pathol 106: 237-249

3. Dyrberg T, Nakhooda AF, Baekkeskov S, Lernmark $\AA$, Poussier P, Marliss EB (1982) Islet cell surface antibodies and lymphocyte antibodies in the spontaneously diabetic BB Wistar rat. Diabetes 31:278-281

4. Like AA, Kislauskis E, Williams RM, Rossini AA (1982) Neonatal thymectomy prevents spontaneous diabetes mellitus in the $\mathrm{BB} / \mathrm{W}$ rat. Science 216: 644-646

5. Like AA, Anthony M, Guberski DL, Rossini AA (1983) Spontaneous diabetes mellitus in the $\mathrm{BB} / \mathrm{W}$ rat. Effects of glucocorticoids, cyclosporin-A, and antiserum to rat lymphocytes. Diabetes 32: 326-330

6. Dyrberg T, Poussier P, Nakhooda F, Marliss EB, Lernmark $\AA$ (1984) Islet cell surface and lymphocyte antibodies often precede the spontaneous diabetes in the BB rat. Diabetologia 26: 159-165

7. Baekkeskov S, Dyrberg T, Lernmark A (1984) Autoantibodies to a 64-kilodalton islet cell protein precede the onset of spontaneous diabetes in the BB rat. Science 224: 1348-1350

8. Laborie C, Sai P, Feutren G, Debray-Sachs M, Quiniou-Debrie MC, Poussier P, Marliss EB, Assan R (1985) Time course of islet cell antibodies in diabetic and nondiabetic BB rats. Diabetes 34: 904-910

9. Yale J-F, Grose M, Marliss EB (1985) Time course of the lymphopenia in BB rats. Relation to the onset of diabetes. Diabetes 34: 955-959 
10. Logothetopoulos J, Valiquette N, Madura E, Cvet D (1984) The onset and progression of pancreatic insulitis in the overt, spontaneously diabetic, young adult BB rat studied by pancreatic biopsy. Diabetes 33: 33-36

11. Srikanta S, Ganda OP, Eisenbarth GS, Soeldner JS (1983) Isletcell antibodies and beta-cell function in monozygotic triplets and twins initially discordant for type 1 diabetes mellitus. $\mathrm{N}$ Engl J Med 308: 322-325

12. Srikanta S, Ganda OP, Gleason RE, Jackson RA, Soeldner JS, Eisenbarth GS (1984) Pre-type 1 diabetes: Linear loss of beta cell response to intravenous glucose. Diabetes 33:717-720

13. Reddy SN, Bibby NJ, Elliott RB (1985) Cellular distribution of insulin, glucagon, pancreatic polypeptide hormone and somatostatin in the fetal and adult pancreas of the guinea pig: a comparative immunohistochemical study. Eur J Cell Biol 38: 301-305

14. Tannenbaum GS, Colle E, Gurd W, Wanamaker L (1981) Dynamic time-course studies of the spontaneously diabetic BB Wistar rat. I. Longitudinal profiles of plasma growth hormone, insulin, and glucose. Endocrinology 109: 1872-1879
15. Reddy S, Bibby NJ, Smith PA, Elliott RB (1985) Rat trypsin: Purification, radioimmunoassay and age-related serum levels in normal and spontaneously diabetic BB Wistar rats. Aust J Exp Biol Med Sci 63: 667-681

16. Nakhooda AF, Poussier P, Marliss EB (1983) Insulin and glucagon secretion in $\mathrm{BB}$ Wistar rats with impaired glucose tolerance. Diabetologia 24: 58-62

17. Ashcroft SJH, Crossley JR (1975) The effects of glucose, N-acetylglucosamine, glyceraldehyde and other sugars on insulin release in vivo. Diabetologia 11: 279-284

Received: 5 May 1986

and in revised form: 23 September 1986

Dr S. Reddy

Department of Paediatrics

University of Auckland School of Medicine

Auckland

New Zealand 